\title{
Un gobierno basado en la felicidad
}

\section{Iván Lazcano Gutiérrez ${ }^{1}$ \\ Universidad Nacional Autónoma de México}

\section{Reseña de libro}

Castellanos Cereceda, R. (2020). Un gobierno basado en la felicidad. Análisis comparativo para promover el bienestar subjetivo desde la política pública. Instituto Nacional de Administración Pública, México. ISBN 978-607-8744-02-2, pp.: 351.

Material original autorizado para su primera publicación en el Journal de Ciencias Sociales, Revista Académica de la Facultad de Ciencias Sociales de la Universidad de Palermo.

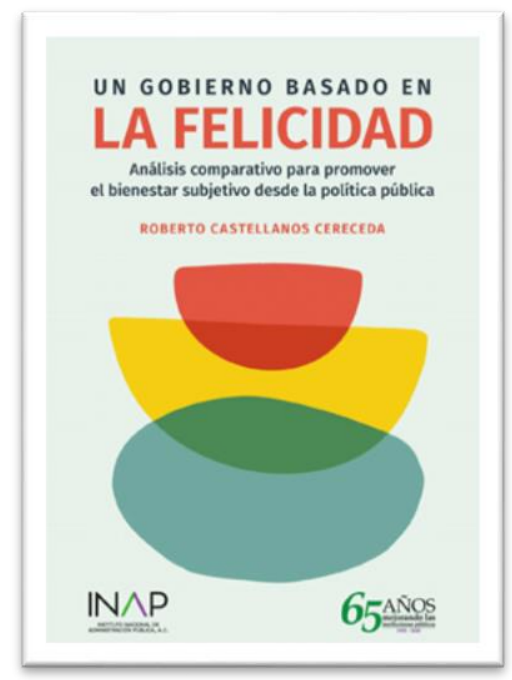

Resumen: La aparición del libro de Roberto Castellanos viene a ocupar un vacío en la literatura de las Ciencias Sociales en México acerca del bienestar subjetivo. El objetivo de este trabajo es analizar la pertinencia y viabilidad del uso del bienestar subjetivo como criterio de decisión y conducción de la política pública en México. Fuera de algunos trabajos colectivos, quizás este libro sea la primera apreciación completa en la materia. Sin duda, fue un acierto la publicación de esta obra por parte del INAP, pues su claridad argumental lo convierte en una fuente de consulta obligada para todos aquel que desee trabajar el tema, tanto desde una perspectiva académica como del diseño de políticas públicas.

El cambio de orientación ideológica que supone la llegada del gobierno del actual presidente de la República en México, ha abierto la puerta a la discusión de varios temas

\footnotetext{
${ }^{1}$ Profesor adscrito al Centro de Estudios en Administración Pública de la Facultad de Ciencias Políticas y Sociales de la UNAM, México. Correo electrónico: ivanlazcano@gmail.com
} 
que habían adquirido una naturalización en la opinión pública a lo largo del periodo neoliberal. Uno de ellos es el relativo a la forma de medir el bienestar en una sociedad.

Como es conocido las economías modernas miden el bienestar colectivo con el indicador del Producto Interno Bruto (PIB), y cuando hablamos a nivel individual el PIB per capita. Sin embargo, con toda la utilidad que puede representar contar con un indicador, éste puede ser engañoso. De entrada, en el primer caso observamos el agregado de la producción de la riqueza y en el segundo, el promedio. Por lo tanto, no estamos en la condición adecuada para medir la situación de las personas. Menos aún si se toma en consideración que a lo largo de estos años de apertura comercial, la riqueza generada se ha concentrado en pocas manos.

Con la finalidad de poder llegar a otras formas de medir el bienestar de las personas, diversos académicos se han concentrado en desarrollar un indicador mucho más útil al momento de registrar el verdadero sentir de los individuos. Uno de ellos, probablemente el más importante sea el Bienestar Subjetivo.

Por tal motivo representa un acierto la aparición del libro Un gobierno basado en la felicidad del doctor Roberto Castellanos Cereceda, publicado por el Instituto Nacional de Administración Pública. Sin lugar a dudas el autor es una de las voces más autorizadas a nivel nacional para tratar el tema. Lo anterior queda fundamentado por los diversos artículos y capítulos de libro que ha escrito previamente sobre el tema a lo largo de los últimos años, así como su participación en múltiples seminarios académicos internacionales en colaboración con especialistas de todas partes del planeta.

Lo primero que hay que señalar es que, a diferencia de la gran mayoría de los trabajos realizados sobre la materia, escritos por economistas e incluso sociólogos, este se aparta de la tendencia al ser un trabajo diseñado desde la perspectiva de la administración pública y de las políticas públicas. Uno de sus objetivos es servir como un conjunto de recomendaciones prácticas y concretas para el diseño e implementación de iniciativas gubernamentales.

Por otro lado, en su conjunto, el libro está estructurado de una forma que permite explorar diversos aspectos del bienestar subjetivo a partir de un eje axial que nos guía a lo largo de sus seis capítulos. Pero, por otro lado, cada uno de los capítulos pueden ser abordados de forma separada en atención del interés que le suscita el tema desarrollado: a partir de una lógica que va de lo general a lo particular; de lo filosófico a las políticas públicas o de los antecedentes históricos a la actualidad.

En este sentido, el primer capítulo está dedicado a la exploración filosófica y teórica del bienestar desde sus fuentes más antiguas, como es el caso de Aristóteles y su noción de la eudaimonia, pasando por algunos de los autores centrales de la ciencia de la policía 
(antecedente de la administración pública) como es el caso de J. H. von Justi, hasta la revisión de loa aproximaciones más recientes sobre la actividad administrativa como Mark Moore y su idea de la creación de valor público.

El segundo capítulo, aborda los aspectos teóricos y las herramientas analíticas. Es en este espacio donde se establece qué es lo que debe entenderse como bienestar subjetivo, así como sus componentes centrales: 1) la evaluación que las personas hacen de sus vidas en general; 2) la felicidad entendida como experiencia afectiva; y 3) el eudemómico, relacionado a la satisfacción de las necesidades vitales y psicológicas básicas, además de la percepción de la percepción de las personas sobre lo valioso de sus proyectos de vida y las posibilidades efectivas de realizarlas. Es importante señalar que el autor aprovecha la ocasión para mencionar algunos retos y dificultades a las que se enfrenta el concepto y sus indicadores concretos.

Vale mencionar que es en este capítulo donde se introduce la importancia de los antecedentes realizados por el utilitarismo de Jeremy Bentham como el primer intento en considerar la felicidad y el dolor como indicadores del bienestar. Asimismo, el autor nos plantea las tres paradojas fundamentales asociadas al bienestar subjetivo; esto es la relación entre riqueza y felicidad: la paradoja de Easterlin; la del crecimiento infeliz y la del campesino feliz.

Una mención aparte merece el capítulo tercero, con la revisión comparativa de la manera en que se han concebido y llevado a la práctica las distintas variantes del bienestar subjetivo a nivel mundial. Concretamente, se exploran los casos de 16 países, destacando uno de los ejemplos más representativos que siempre viene a la mente cuando se habla del tema como el Reino de Bután. A este habría que sumar el caso de Francia por el papel fundamental que representó el reporte elaborado por la Comisión Stiglitz-Sen-Fitousi. Resulta un acierto la revisión equilibrada de casos europeos, americanos y asiáticos.

Posteriormente, el capítulo cuatro retoma los casos revisados previamente, con la finalidad de sistematizarlos. De esta forma, se identifican aquellos elementos que tienen en común y de diferentes a partir de las siguientes variables: a) los conceptos definidos; b) las mediciones diseñadas; c) los usos de estas mediciones en la política pública, así como d) el proceso decisorio para medir y emplear en las acciones de gobierno. En este sentido, por ejemplo, cabe destacar que en cuanto a los tres componentes del bienestar subjetivo planteados en el segundo capítulo, se aprecia que la mayoría de los casos están construidos con base en los dos primeros.

Merece la pena destacar algunas de las tendencias identificadas que se derivan del análisis. Por un lado el hecho de que la noción del bienestar subjetivo se presta para un análisis multidimensional, por lo que tiene un alcance y aplicación transversal en diversos 
ámbitos de las vidas de las personas. Se trata de dos propensiones que están íntimamente vinculadas. Más importante, tal vez, es la tercera tendencia señalada por Roberto Castellanos, relativa a la vinculación entre las condiciones materiales (objetivas) que experimentan en sus vidas las personas, junto con las oportunidades que realmente tienen delante de sí para vivir sus vidas. Esto se vuelve fundamental porque pone el énfasis en un aspecto polémico en las Ciencias Sociales, especialmente en la sociología, que es el del peso de la estructura frente a la libertad de agencia individual. Por mucho tiempo se han tomado aproximaciones unidimensionales y unidireccionales para comprender las explicaciones de la calidad de vida de las personas, sobredeterminando el peso de una o la infinita posibilidad de la otra.

El libro cierra con sendos capítulos dedicados al caso de México. En particular, el capítulo quinto explora el experimento denominado Encuesta de Bienestar Autorreportado (BIARE) realizado por Instituto Nacional de Geografía y Estadística (INEGI) en 2012. Tal como se mencionó previamente, este proyecto piloto mexicano descansa, como la mayoría de estos intentos, en los dos primeros componentes, dejando de lado el eudemónico, aun cuando el mismo autor nos refiere aquellos elementos destinados a atenderlo.

En cuanto a los resultados que se desprenden de las mediciones, se aprecia que de los indicadores relacionados con el bienestar subjetivo la mayoría de ellos se encuentran por encima del promedio. El siguiente paso consiste en el análisis de las correlaciones entre los indicadores. Así, por ejemplo, se observa una correlación moderada y fuerte entre satisfacción y felicidad con satisfacción y afectos positivos junto con satisfacción y balance afectivo. En otras palabras, según señala el autor, es esperable una relación entre la satisfacción de la vida y la felicidad. Por otro lado, el capítulo es complementado con análisis a partir de diferentes enfoques, como el realizado por factores sociodemográficos, el principal de ellos entre mujeres y hombres y que reporta una ligera superioridad el caso de las primeras. A ello se suman otros cruces como el que se presenta con el gasto per capita o con el nivel de instrucción, por mencionar solo algunos.

Finalmente, el capítulo sexto y último está dedicado a explorar la factibilidad y pertinencia de la utilización del bienestar subjetivo en las políticas públicas puestas implementadas por la administración pública en México. La aparición del libro de Roberto Castellanos viene a ocupar un vacío en la literatura de las Ciencias Sociales sobre el bienestar subjetivo en México. Fuera de algunos trabajos colectivos, quizás sea el primer trabajo completo sobre la materia. La publicación de esta obra por parte del INAP fue un verdadero acierto que, sin duda, se convertirá en una fuente de consulta obligada para todos y todas aquellos/as que desee trabajar el tema, tanto desde una perspectiva académica como desde el diseño de políticas públicas. 